\title{
Social and medical models of disability and mental health: evolution and renewal
}

\author{
— Cite as: CMAJ 2019 January 7;191:E16-8. doi: 10.1503/cmaj.181008
}

CMAJ Podcasts: author interview at https://soundcloud.com/cmajpodcasts/181008-medsoc

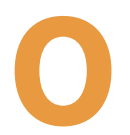

ver the last 6 decades, many published commentaries, from both within and outside the medical community, have criticized medicine's characterization and management of mental illness and disability. These critiques have often referenced the "medical model," a term that has multiple meanings but has almost always been used pejoratively. Prominent critics have included disability scholars and self-advocates, who attacked the so-called "medical model" and espoused an alternative "social model," which characterizes disability as the product of an unaccommodating and oppressive society, rather than an individual and medical problem.

The terms "social model" and "medical model" have frequently been used to highlight opposing views of disability, but there has been little historical examination of their origins and evolving meanings. ${ }^{1}$ As a result, clinicians have had limited access to information about what these concepts mean to patients, making it difficult to respond adequately to the concerns they raise. For physicians, fully embracing social-model views would require political engagement and a greater focus on societal, rather than individual, problems. Even if most physicians do not adopt these roles, increased awareness of disability perspectives and familiarity with critiques of the medical model may help them to identify new ways of improving care for their patients, while also enhancing opportunities and support for clinical trainees and colleagues with disabilities.

The critique of the medical model originated in the psychiatry literature and has taken various forms since psychiatrist Thomas Szasz coined it in the mid-1950s. ${ }^{2}$

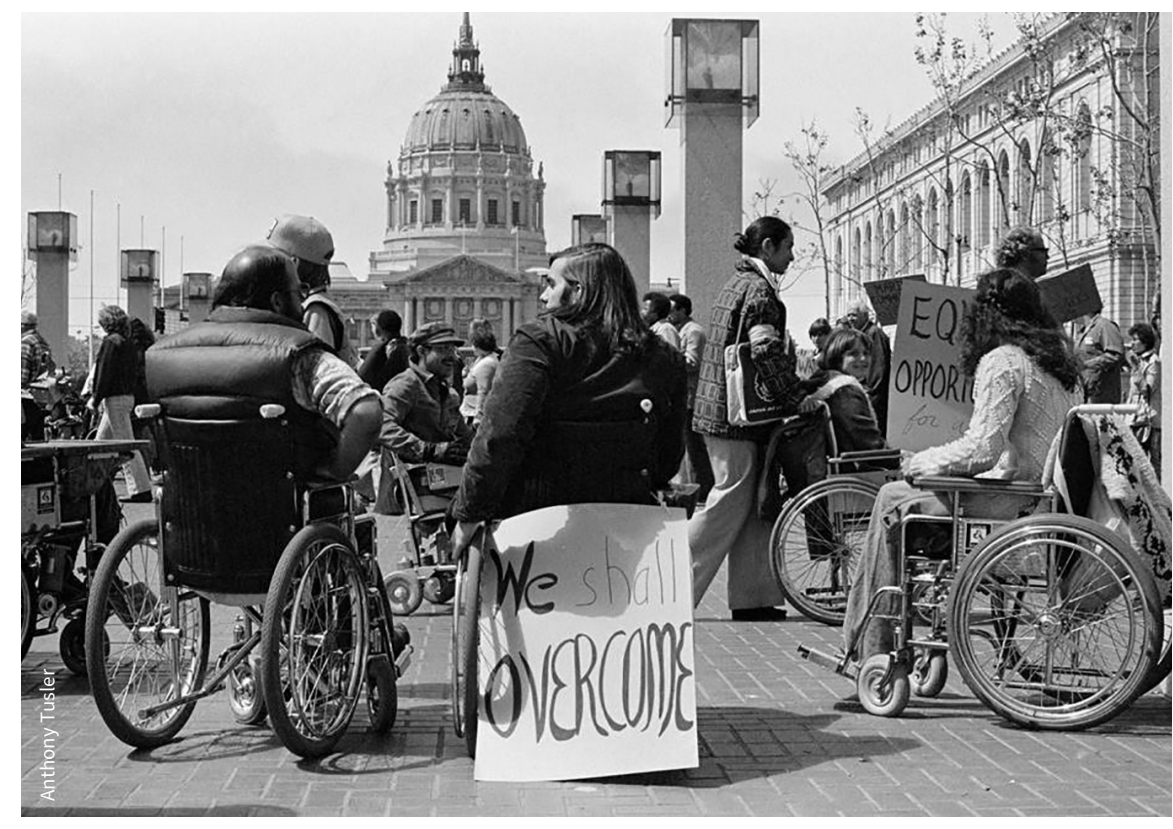

Disability self-advocates rally in San Francisco, California, in 1973 for improved governmental and social supports, and an end to the oppression of people with disabilities. This image is reprinted with permission from Anthony Tusler, AboutDisability.

One version, an antireductionist view, lamented the tendency of medicine to reduce disease and disability down to physiochemical factors. This genre of criticism was popular among health professionals, who called for reforming medical practice to make clinicians more sensitive to the complex psychosocial aspects of health and illness.

A second, exclusionist strain - initially espoused by Szasz - did not seek to reform medicine, but to exclude certain areas from medical oversight. Proponents of exclusionist views argued that medical intervention in specific realms - like mental health and disability - was stigmatizing or oppressive. Some suggested that these issues required societal reform, not individual treatment.
Most physicians have found antireductionist critiques of medicine to be more palatable than calls for exclusion, because antireductionist reforms do not question the fundamental value of medicine in treating individuals with mental illness and disability. One prominent proponent of an antireductionist perspective in the 1970s was psychiatrist George Engel. He took on the medical model, calling for a move away from reductive natural science approaches, in favour of an alternative "biopsychosocial model." Engel distinguished his view from Szasz and other "exclusionists" (Engel's term) by arguing that mental illness was a disease, and that its biological causes should not be dismissed. ${ }^{3}$ At the same time, Engel suggested that medicine required a more 
nuanced view of disease, which included recognition of psychosocial issues along with physiochemistry. ${ }^{4}$ Engel's biopsychosocial model retained a dominant role for physicians, while calling on them to look beyond laboratory findings to consider a patient's social environment.

Although Engel did not specifically address disability, his biopsychosocial model was widely influential among clinicians who specialized in this area. An antireductionist form of medical model critique was prominently presented in the World Health Organization's classification of disability, published in 1980 (since updated: www.who.int/classifications/ icf/en). Similar arguments were also espoused in other health-related books from this period, including Genetic Disorders and Birth Defects in Families and Society (1984), which featured chapters on the medical, ethical and social aspects of disability, written by physicians, patient advocates and clergy. In these forums, physicians acknowledged critiques of the medical model and accepted outside advice on how to make medicine more sensitive to psychosocial aspects of disability. However, this was done without questioning the medical view of disability as a problem that could be clinically defined and treated.

Outside of medicine in the 1970s, clinical psychologists and sociologists influenced by Szasz - took up and expanded exclusionist perspectives, applying this strain of medical model critique to mental illness, behaviour and intellectual disabilities. Clinical psychologist George Albee was a vocal critic of psychiatric approaches to mental health, which he argued inappropriately pathologized people's "problems of living." 5 Similarly, clinical psychologist Wolf Wolfensberger criticized the application of the medical model to intelligence and behaviour. Albee and Wolfensberger called for alternative approaches, which removed these issues from medical oversight and focused on reforming social institutions to be more supportive of individual differences. Unfortunately, both men's views were met with derision by many of their medical colleagues, and their perspectives remained little known by physicians.
Sociologists Erving Goffman and Kenneth Irving Zola also adopted an exclusionist strain of medical model critique, highlighting the isolation, stigmatization and medicalization of deviant behaviour. ${ }^{6,7}$ Zola also helped to adapt Szasz's exclusionist view of mental illness to encourage new perspectives on physical disabilities as a social rather than a medical issue. In doing so, Zola - who identified as having a physical disability - contributed in the 1980 s to the burgeoning American disabil-

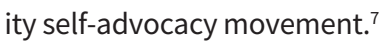

At the same time, British scholar Michael Oliver adopted an exclusionist strain of the medical model critique in his formulation of the social model of disability. ${ }^{8}$ The social model argued that disability was a status imposed on people with various forms of impairment, and therefore that disability was a political, not a health, issue. Social model proponents held that the medical model viewed personal impairment as the sole cause of disability, making an individual's body the appropriate target for intervention. Oliver argued that disability was distinct from impairment, and instead was the product of an unaccommodating society. From a ering new perspective for many people with disabilities, some struggled with the implication that their disability was entirely the result of social oppression, because this seemed to suggest that their individual impairments should be ignored.

During the 1990s, feminist disability scholars and self-advocates, including Jenny Morris and Liz Crow, called for a "renewed social model of disability," one that largely retained an exclusionist perspective, but acknowledged that even in a world without disability discrimination, impairment would have negative individual impacts. ${ }^{10}$ Crow argued that the negative effects of impairment, like chronic pain, can on their own interfere with one's social engagement, and may be beneficially mitigated by medical intervention. ${ }^{10}$

Since the 1990s, proponents of the social model of disability have widely embraced the view that impairment and disability interact, and that the individual challenges of impairment should not be disregarded. Nonetheless, many disability self-advocates continue to express substantial distrust in the medical community and its approaches.

\section{Physicians have an important role to play in recognizing the unique strengths and equal competency of people with disabilities}

social model perspective, medicine's focus on treating impairment reified the widespread conception of disability as an individual tragedy, rather than the outcome of oppressive social perceptions and arrangements. One way to combat oppression, social model advocates suggested, was to exclude disability from medical oversight.

Of course, everyone occasionally requires medical care, and for people with certain disabilities - especially progressive, chronic or painful conditions - medical interventions may be necessary to maintain well-being and livelihood. ${ }^{9}$ Although the social model was an empow-
How then can physicians, as helping professionals, enhance their care and support for people with disabilities? One option is greater political engagement: promoting the view that disability should be seen as a valued form of human diversity, rather than an individual and tragic problem to be lamented and solved.

Many physicians may believe that their strengths for fomenting change would be best realized working with individuals in the clinic, rather than in the political arena; and indeed, there remains plenty of work to be done within the clinical professions. One key area is mentorship: teaching trainees about 
disability perspectives, and why many self-advocates have adopted and maintained an exclusionist form of medical model critique.

Another very important avenue is in recruiting and supporting people with disabilities to join and thrive in the clinical professions. ${ }^{11}$ Physicians have an important role to play in recognizing the unique strengths and equal competency of people with disabilities as clinical professionals. Many of these qualified individuals have recounted being made to feel out of place in medical culture. Fundamental changes to medical training programs and institutions that normalize disability accommodations for students, residents, fellows and practitioners have yet to be made. ${ }^{12}$

If physicians want to take an important step in the evolution and renewal of their profession, to show that medicine is more supportive and accepting than many peo- ple with disabilities have, understandably, come to believe, then embracing a much more nationally representative group of people with disabilities to become full participants and respected members of the clinical professions would be an important and welcomed start.

\section{References}

1. Hogan AJ. Moving away from the "medical model" the World Health Organization's classification of disability. Bull Hist Med. In press.

2. Szasz TS. Some observations on the relationship between psychiatry and the law. AMA Arch Neurol Psychiatry 1956;75:297-315.

3. Engel GL. The need for a new medical model: a challenge for biomedicine. Science 1977;196:129-36.

4. Brown TM. George Engel and Rochester's biopsychosocial tradition: historical and developmental perspectives. In: Frankel RM, Quill TE, McDaniel SH, editors. The biopsychosocial approach: past, present, and future. Rochester (NY): University of Rochester Press; 2003.

5. Albee GW. To thine own self be true. Am Psychol 1975;30:1156-8.
6. Goffman E. Asylums: essays on the social situation of mental patients and other inmates. Garden City (NY): Anchor Books; 1961.

7. Zola IK. Socio-medical inquiries: recollections, reflections, and reconsiderations. Philadelphia: Temple University Press; 1983.

8. Oliver M. The politics of disablement. London (UK): Macmillan; 1990.

9. Linker B. On the borderland of medical and disability history: a survey of the fields. Bull Hist Med 2013; 87:499-535.

10. Crow L. Including all of our lives: renewing the social model of disability. In: Barnes C, Mercer G, editors. Exploring the divide: illness and disability. Leeds (UK): Disability Press; 1996.

11. Shakespeare T, lezzoni LI, Groce NE. Disability and the training of health professionals. Lancet 2009; 374:1815-6.

12. Vogel L. Major gaps in supports for medical trainees with disabilities. CMAJ 2018;190:E632-3.

\section{Andrew J. Hogan MA PhD}

Department of History, Creighton

University College of Arts and Sciences, Omaha, Neb.

This article has been peer reviewed. 